\title{
Da sedução à morte: uma análise da novela judaica Judite sob a perspectiva de gênero
}

\author{
From seduction to death: an analysis of the Judith \\ Jewish novel from a gender perspective
}

\section{De la seducción a la muerte: un análisis de la novela judía Judita bajo la perspectiva de género}

\author{
Sue'Hellen Monteiro de Matos*
}

\begin{abstract}
RESUMO
As novelas bíblicas veterotestamentárias são lidas, relidas e recepcionadas ao longo dos tempos, além de nos possibilitar diversas óticas de leituras. Neste artigo analisaremos o livro de Judite considerando seus aspectos redacionais, literários e contexto histórico no qual ele fora escrito, além de propor um ensaio de uma leitura sob a perspectiva de gênero desta novela, tendo em vista as relações de poder que perpassam toda a narrativa.

Palavras-chave: Judite; novela bíblica; contexto histórico; análise de gênero; relações de poder.
\end{abstract}

\begin{abstract}
The biblical Old Testament novels are read, reread and received over time, as well as enabling us to have different reading optics. In article we will analyze the book of Judith considering its editorial aspects, literary and historical context in which it was written, besides proposing an essay of a reading from the gender perspective of this novel, in view of the relations of power that permeate the whole narrative.

Key-words: Judith; biblical novel; historical context; gender analysis; power relations.

\section{RESUMEN}

Las novelas bíblicas veterotestamentarias son leídas, relesas y recibidas a lo largo de los tiempos, además de posibilitar diversas ópticas de lecturas. En este artículo analizaremos el libro de Judit considerando sus aspectos redactivos, literarios y contexto histórico en el cual él fue escrito, además de proponer un ensayo de una lectura bajo la perspectiva de género de esta novela, teniendo en vista las relaciones de poder que atravesan toda la narrativa. Palabras clave: Judit; novela bíblica; contexto histórico; análisis de género; relaciones de poder.
\end{abstract}

\section{Introdução}

Violência, guerra, beleza, sedução e morte, são temas que perpassam a narrativa do livro de Judite. Um livro que narra o heroísmo de uma mulher que de viúva "bela, recatada e do lar" passa a ser agente da salvação

* Doutoranda em Ciências da Religião pela Universidade Metodista de São Paulo e professora da Universidade Metropolitana de Santos. Bolsista CAPES. E-mail: suehellen.matos@gmail.com 
do povo de Betúlia, que estava prestes a ser invadida pelo exército assírio. Judite, então, usa da sedução e degola o general Holofernes. A cena narrada nos causa estranheza pela violência nas mãos de uma mulher, mas também certo alívio, pois finalmente o general estava morto.

Esta cena não se restringiu apenas à narrativa bíblica, antes, inspirou artistas a retratem a decapitação. Caravaggio, em 1599, pintou Judite e Holofernes, apresentando Judite, com aparência jovem e segura do que ia fazer, cortando a cabeça de Holofernes, e ao lado sua serva, de aparência idosa e com expressão de preocupação, segurando o alforje; e Holofernes com expressão de espanto e sangue jorrando de seu pescoço. O quadro Judite decapitando Holofernes foi pintado por Artemisisa Gentileschi, em 1620, que retrata Judite, plena e segura para matar. Não há transparência nenhuma de hesitação ou temor para degolar Holofernes. O general, por sua vez, é retratado bêbado, mas um pouco consciente para tentar lutar, mas sendo segurado pela serva de Judite. ${ }^{1}$ Nota-se que ambas as pinturas colocam a serva de Judite na cena, enquanto a narrativa bíblica Judite está sozinha no quarto, e sua serva a espera no lado de fora $(13,1-12) .{ }^{2}$ Provavelmente há a junção de toda a cena descrita na narrativa, visto que a serva também fez parte da ação ao colocar a cabeça de Holofernes no alforje de alimentos para saírem do acampamento do general.

Considerando os ecos da narrativa bíblica ao longo dos tempos, nosso ensaio tem por objetivo compreender os aspectos gerais (texto e contexto), análise da narrativa, e, por fim, um ensaio de Judite sob a perspectiva de gênero.

\section{Aspectos gerais: texto e contexto}

Muito se discute sobre da redação do livro de Judite. Qual a língua original escrita? Quando foi escrito? Quem escreveu? Essas são algumas questões que abordaremos nesta seção.

As versões mais antigas do livro de Judite se encontram em manuscritos gregos. Entretanto, existe o debate em relação ao "texto original" do livro de Judite entre os/as pesquisadores/as. Teria sido escrito em hebraico ou aramaico e depois traduzido para o grego? Mesmo não tendo nenhum códice hebraico ou aramaico para corroborar com esta hipótese há o consenso entre a maioria dos/as estudiosos/as sobre a origem semita do livro devido à linguagem do texto grego (VÍLCHEZ LÍNDEZ, 2006, p. 277).

Tendo em vista o texto grego que nos fora transmitido, é necessário compreender o contexto no qual foi escrita a narrativa. No entanto, numa

\footnotetext{
Fizemos uma primeira observação das obras apenas para sintetizar a descrição dos quadros.

Neste artigo as citações bíblicas são da BÍBLIA DE JERUSALÉM, 2006.
} 
primeira leitura, a narrativa nos leva ao tempo do domínio assírio e babilônico, isso se levarmos em consideração que o texto se trata de um relato histórico. Deste modo, antes de entender o contexto, se faz necessário compreender o gênero do livro.

Há uma diversidade de classificações do livro de Judite. A Septuaginta classifica-o como histórico devido às suas inúmeras informações a respeito de nomes, lugares, datas, e até mesmo o estilo de prosa narrativa. Entretanto, um estudo atento e com auxílio de outras fontes, observa a imprecisão dos dados geográficos e históricos (GALAZZI; RIZZANTE, 2001, p. 17).

Outros estudiosos classificam como novela, ou como novela bistórica, outros como conto popular. Há pesquisadores, como Moore que relacionam o livro de Judite com o estilo dos apocalipses, e os que aplicam o gênero da narração edificante (VÍLCHEZ LÍNDEZ, 2006, p. 281). Para Galazzi e Rizzante (2001, p. 17-18), o gênero do livro de Judite é o das memórias populares, presente nos livros de Josué, Juízes, Samuel e alguns capítulos dos Reis. Neste gênero, os elementos recolhidos pela memória popular adquirem uma dimensão paradigmática e ocupam um espaço na discussão sociológica e teológica que acontecia na época da redação do texto.

Entretanto, não podemos classificá-la como memórias populares, pois todo o livro apresenta uma narrativa que tem uma estória a ser desenvolvida e encerrada, na qual o leitor aguarda pelo desfecho. Deste modo, o livro de Judite deve ser classificado como novela, visto que, novela, conforme Wills (2002, p. 5), é, resumidamente, uma "narrativa de ficção popular escrita, expandida significativamente para além de um único episódio, que se concentra no caráter e na virtude". É importante ressaltar que o escrito popular aqui não se refere ao número de leitores do texto, mas a seu uso "não oficial" e de entreterimento (WILLS, 2002, p. 6).

Ademais, Wills (2002, p. 4-5) afirma que a novela judaica surge no período grego-romano para recontar e compor novas estórias, com o objetivo de entreter através da narrativa em prosa, fazendo uso de meios diretos e emocionais para cumprir tal objetivo. Conforme o autor, os temas típicos das novelas são: amor, perigo, aventura, emoção, virtude, caráter, piedade e oração. A partir de então, o autor classifica como novelas judaicas o texto grego de Ester, o texto grego de Daniel, Tobias, Judite e texto de José e Aseneth. Nestas narrativas, os protagonistas são figuras pouco conhecidas ou totalmente desconhecidas da história judaica juntamente com os seus temas principais: a piedade e identidade judaica. Normalmente, as mulheres são protagonistas da narrativa, assim como nas novelas gregas antigas. Entretanto, nas novelas gregas a protagonista é sempre colocada junto a um parceiro 
numa união romântica, já nas novelas judaicas as mulheres são apresentadas, normalmente, sozinhas, como por exemplo, Judite.

Considerando o período greco-romano em que as novelas judaicas surgiram, possivelmente o livro de Judite tenha sido escrito no século II a.E.C. (WILLS, 2002, p. 89). Nesta época, os Selêucidas (198 a.E.C.) dominam a Palestina. Sob um governo de Antíoco IV, um dos mais violentos desta dinastia. Há a proibição de diversas leis religiosas judaicas, entre elas o cumprimento do sábado e a prática da circuncisão, além de profanar o templo instalando uma estátua de Zeus, o que desencadeia a revolta dos Macabeus (D’AMICO, 1993, p. 11).

Reduzindo um pouco o período, Vílchez Líndez (2006, p. 290-291) propõe que o texto tenha sido escrito próximo à vitória dos Macabeus sobre os selêucidas, no final do reinado de Antíoco IV (175-164 a.E.C.), ou no começo do reinado de Demétrio I (162-150 a.E.C.), visto que a religiosidade apresentada por Judite se assemelha com os assideus dessa época; o apreço pelas instituições: o templo, o sacerdócio, o conselho dos anciãos; a idealização do povo de Israel, como no livro de Daniel; traços tipicamente helenistas já incorporados pelo povo, como o uso de grinaldas $(3,7)$, coroas de oliveira $(15,13)$, atitude nos banquetes $(12,15)$.

Considerando este período histórico e o uso semítico do grego, a autoria do livro de Judite se aproxima ao grupo que escreveu o Primeiro Livro dos Macabeus e o texto grego de Ester. Possivelmente o livro de Judite representa o pensamento de um grupo que somou forças com Judas Macabeu na guerra pela libertação de Judá (GALAZZI; RIZZANTE, 2001, p. 15).

\section{Análise da narrativa}

A novela de Judite apresenta seus personagens no decorrer da narrativa. Alguns com maiores detalhes, outros apenas descritos na cena, e outros que, mesmo sem nome, desempenham papel importante na trama, como é o caso da serva de Judite que a acompanha em sua jornada ao acampamento assírio $(10,10)$ até o retorno a Betúlia com a cabeça de Holofernes em seu alforje (13,9-10). Por exemplo, Nabucodonosor é apresentado como aquele que reinou sobre os assírios $(1,1)$, e versículos seguintes, como o próprio rei dos Assírios (1,7). Capítulos seguintes, o personagem é apresentado como o rei de toda terra (6,4). Brevemente se fala de Arfaxad, rei de Ecbátana $(1,2)$ contra o qual Nabucodonosor inicia sua campanha militar, descrita na narrativa. Holofernes é apresentado como general do exército de Nabucodonosor $(2,4)$, o qual comandará a campanha militar contra a Judéia.

Judite, por sua vez, é apresentada com maiores detalhes. Em 8,1-8 há a descrição de sua genealogia, da sua viuvez, de suas vestimentas (vestia-se 
de pano de saco e cobria-se com "manto de sua viuvez"), de sua beleza, de sua função administrativa, e de sua conduta e fé, pois "não havia quem lhe recriminasse uma palavra má, pois era muito temente a Deus" (v.8). Essas características vão sendo desenvolvidas no texto, como no capítulo 9 há uma demonstração de sua piedade, quando Judite se prostra com rosto por terra para orar. Entretanto, há características que são alteradas, como suas vestimentas. A personagem deixa a sua viuvez, e se veste para "seduzir os homens", como estratégia de seu plano para findar a guerra - "calçou sandálias nos pés, colocou colares, braceletes, anéis, brincos, todas as suas joias, embelezando-se a fim de seduzir os homens que a vissem" $(10,4)$.

Esse, e outros destaques à beleza e a coragem de Judite demonstram a influência da novela grega na narrativa, uma vez que no mundo grego há alguns mitos que falam da extraordinária beleza de mulheres e homens, divindades ou não, e também dos aspectos guerreiros. Afrodite era denominada Deusa do amor e da beleza, cujo título de "mais bela" era disputado com Hera e Atena. Helena é relata como uma mulher bela, casada com o rei de Esparta, que se apaixonou por Páris e fugiu com ele para Tróia, desencadeando a guerra de Tróia. O mito das Amazonas, no qual essas mulheres guerreiras são descendentes de Ares, Deus da guerra, e da ninfa Harmonia. Usam os homens apenas para trabalhos servis, e esporadicamente, para perpetuação da espécie, e tem a Deusa Ártemis como protetora (MARQUES, 2008, p. 51-52). Deste modo, de acordo com Marques (2008, p. 52), "a construção do corpo de Judite se aproxima do corpo das mulheres gregas mitificadas, deusas ou não".

Todavia, ao mesmo tempo em que Judite se aproxima das mulheres gregas, ela se opõe a elas, pois sua beleza está a serviço de Javé e em defesa do povo judeu, uma vez que as mulheres gregas eram vistas, na época em que fora escrita a novela, como "perdição" ao homem judeu. Deste modo, o uso de sua beleza e sedução é limitada para cumprir a salvação do povo, até mesmo porque ao final da novela, Judite volta à sua vida recatada.

Outrossim, LaCocque (apud MARQUES, 2008, p. 52) afirma que "o fato da heroína não aceitar se casar novamente e se fazer acompanhar por sua serva - 'abra, palavra que designa a escrava favorita - é uma característica da tragédia e da comédia grega". Assim, apesar da narrativa de Judite ser uma reação subversiva dos judeus piedosos contra o processo helenização, ela evidencia a influência do pensamento helenista na sociedade judaica.

A novela de Judite, de acordo com Wills (2002, p. 90) pode ser dividida em duas partes: a) a aparição no horizonte de Holofernes, geral de Nabucodonosor, e seu grande exército (1-7); b) resgate heroico aldeia judaica 
Betúlia pela piedosa e bela viúva judia, Judith. Embora alguns estudiosos questionassem a possibilidade de inserções na narrativa de Judite como no ocorre no livro de Daniel, segundo o autor, esta divisão deve ser considerada como capítulos da novela, visto que "existe um fio narrativo de ação ascendente, desfecho e ação de queda, embora seja desenvolvido por meio de cenas individuais" (WILLS, 2002, p. 91).

Resumidamente, a novela de Judite se inicia com a campanha militar de Nabucodonosor contra o rei Arfaxad, vencendo-o e celebrando com seu exército por 120 dias $(1,1.16)$. Como o intuito de Nabucodonosor era ser o "rei de toda terra", inicia uma campanha ocidental, para a qual convoca o seu imediato, general Holofernes (2,1-20). O general inicia sua campanha com muita violência, matando e destruindo os lugares de culto - "Mas ele não deixou de devastar seus santuários e de cortar suas árvores sagradas. Fora autorizado a exterminar todos os deuses da terra, de maneira que todos os povos adorassem só a Nabucodonosor, e que todas as línguas e todas as tribos o invocassem como deus" $(3,8)$.

Com toda essa campanha vitoriosa e violenta de Holofernes, o povo que habitava na Judéia ficou aterrorizado e temeroso com a possibilidade da destruição do Templo. Joaquim, o sumo sacerdote toma providências e pede que os habitantes de Betúlia e Betomestaim ocupem as passagens das montanhas para impossibilitar a passagem do exército até Jerusalém (4,1-8). E, diante do medo, todo o povo, homens, mulheres, crianças, forasteiros, mercenários, vestiram pano de saco, jejuaram, ofereceram holocaustos e suplicaram a Deus "para que visitasse, com seu favor, toda a casa de Israel" (4,9-15).

Mudando a cena, a narrativa retorna ao acampamento do exército assírio. Aquior, o chefe dos filhos de Amon, informa a postura dos israelitas frente ao cerco de Holofernes, faz um resumo da história dos israelitas, da saída da terra dos caldeus até o retorno da diáspora, e propõe que Holofernes investigue se há pecado nos israelitas, pois se assim for, Deus os castigará e a vitória de Holofernes é garantida (5,1-22).

Entretanto, Holofernes não vê com bons olhos o conselho de Aquior, pois para ele ninguém é deus além de Nabucodonosor (6,2). Além disso, o general ostenta a sua força militar. Sendo assim, ele envia Aquior aos israelitas, deixando-o amarrado aos pés do monte. Os israelitas o conduzem para a cidade de Betúlia. Ozias, um dos anciãos da cidade, o questiona sobre o que acontecera. Ao saberem da postura de Aquior e a de Holofernes o povo reunido em assembleia, ora ao Senhor para que humilhe Holofernes. Então, Aquior é recebido com banquete na casa de Ozias (6,1-21).

No dia seguinte, como a narrativa descreve, Holofernes ordena que seu exército avance contra Betúlia com toda a sua força, cercando-os. Os israeli- 
tas, ao perceberem o cerco assírio com toda a infantaria, carros e cavaleiros, se abateram. No entanto, não fora somente o ânimo do povo afetado, mas com o passar dos dias, a situação ficou precária devido à falta de água. Diante disso, o povo pede a Ozias que entregue a cidade em paz ao general. Por sua vez, o ancião solicita ao povo que resistam por mais cinco dias, que "Deus volverá com sua misericórdia" (7,1-30).

Quando tudo parecia perdido, eis que surge a nossa heroína. Até então, as mulheres apareciam apenas como menções na hora de referir-se ao povo, mas sem nenhuma voz ou atuação. Judite, viúva, temente a Deus, bela e encantadora, se dirige aos anciãos com uma palavra profética: ${ }^{3}$

Quem sois vós, que hoje tentais a Deus e vos colocais acima dele no meio dos filhos dos homens? Agora colocais À prova o Senhor Todo-poderoso! Jamais compreendereis coisa alguma! [...] Não se encurrala a Deus como um homem, nem se pode submetê-lo como a um filho de homem. Por isso, esperando pacientemente a salvação dele, invoquemo-lo em nosso socorro. Ele ouvirá a nossa voz, se for do seu agrado (8,11-17).

Diante de sua palavra, Ozias reconhece a palavra de Judite, e acrescenta que "não há quem contradiga tuas razões". Interessante notar que nesse momento, a beleza de Judite não é ressaltada, mas a sua inteligência, bondade e piedade (8,29-30). E, por ser mulher piedosa, Ozias pede que ela interceda pelo povo. Judite, não apenas ora, mas afirma que fará algo para ser lembrado (8,32-35). Neste ponto, a narrativa desperta no leitor a curiosidade para saber qual será a ação desta mulher que surge no meio da estória,

A seguir temos a oração de Judite pedindo socorro a Deus. Oração que começa com a denúncia da violência sexual $(9,2)$, provavelmente violência gerada pela guerra. Após relembrar os fatos passados em sua oração, Judite roga para que a arrogância do general seja quebrada pela mão de uma mulher $(9,10)$, e pede que Deus a dê "uma linguagem sedutora, para ferir e matar" $(9,13)$. Temos, portanto, alguns indícios do que está por vir no desenvolvimento da narrativa.

Então, Judite se "embeleza a fim de seduzir os homens que a vissem", e parte com sua serva para o acampamento assírio. Com sua astúcia ao falar, ela engana os soldados que encontra no caminho, e consegue chegar até o general. Ao vê-la, Holofernes e seus soldados que ali estavam, ficam admirados pela beleza de Judite (10,1-23).

O general conversa com Judite a fim de saber o que acontecera com ela para "fugir" do povo de Betúlia. Ao final do diálogo, a heroína é exaltada

3 Embora estejamos no campo da ficção, a característica da fala de Judite tem seu teor profético no que diz respeito à repreensão da atuação da liderança religiosa judaica. 
pela sua beleza e inteligência - "De um extremo a outro da terra não existe mulher semelhante em beleza e em inteligência no falar" $(11,21)$. A Judite é oferecido comida e vinho, mas ela recusa para não haver nenhuma falta sobre ela, semelhante ao personagem Daniel que recusa comer as iguarias do rei. Percebendo que ganhara a confiança de Holofernes, Judite solicita ao general conceder a ela as saídas noturnas do acampamento para orar e se purificar. O pedido é atendido, e Judite mantém a sua rotina por três dias (12,7-9).

Cada ação de nossa heroína é muito bem pensada. Assim, no quarto dia, Judite é convidada ao banquete do general. Ela, novamente, se "adornou com suas vestes e com todos os seus enfeites femininos". Holofernes ao vê-la, seu coração "foi arrebatado por ela, e seu espírito se agitou. Estava possuído de um intenso desejo de se unir a ela. Desde o dia que a vira, espreitava um momento favorável para seduzi-la" $(12,16)$. O desejo de Holofernes por Judite estava nítido, e ela entra neste jogo de sedução. O general a convida para beber, porém ela bebe do que a sua serva havia preparado. Por sua vez, ele empolgado com a possibilidade de possuí-la, bebe demasiadamente. Ao fim do banquete, os oficiais se retiram, e Judite é deixada na tenda sozinha com o general. À sua serva, solicita que a espere do lado de fora do quarto. A cena está dada. O que acontecerá? Judite deixará ser seduzida? Para o leitor que tem acompanhado a novela já sabe que ela está tramando algo.

Então, Judite "aproximando-se do leito, pegou a cabeleira de sua cabeça e disse: 'Faze-me forte neste dia, Senhor Deus de Israel'. Golpeou por duas vezes o seu pescoço, com toda a força e separou a sua cabeça." (13,7-8). Judite entrega a cabeça a sua serva, e ambas seguem para fora do acampamento, como de costume para orar. Entretanto, elas seguem o caminho até Betúlia. Ao chegar à cidade com a cabeça de Holofernes, Judite é exaltada por seu feito $(13,11-20)$.

A narração desta cena se assemelha, em alguns aspectos, com o relato de Jael assassinando Sísara com uma estaca cravada em sua têmpora (Jz 4,1722). No capítulo seguinte é exaltada por tal feito (Jz 5,24-27). Nota-se que o autor, além das influências gregas, conhecia muito bem as histórias dos juízes, especialmente o cântico de Débora (WHITE, 1992, p. 5).

Com a morte de Holofernes, a narrativa se encaminha para o seu desfecho. Os judeus assaltam o acampamento assírio sob ordem da própria Judite. O amonita, Aquior, circunda-se e é integrado ao povo (14,1-15,7). A guerra findou-se, tempo de celebrar! O sumo sacerdote e os anciãos louvam a nossa heroína - "Tu és a glória de Jerusalém! Tu és o supremo orgulho de Israel! Tu és a grande honra de nossa raça!”. Em resposta, Judite entoa um cântico de ação de graças a Deus (16,1-20). A novela se encerra com o relato 
da velhice e morte de Judite, de um modo semelhante ao encerramento das histórias dos juízes.

\section{Judite sob a perspectiva de gênero}

Algumas considerações preliminares são importantes para observarmos Judite a partir desta perspectiva. Primeiramente, falar de gênero não é falar de "mulher", mas sim das relações sociais entre os sexos. De acordo com Scott (1990, p. 21), "gênero é um elemento constitutivo de relações sociais baseado nas diferenças percebidas entre os sexos, e o gênero é uma forma primeira de significar as relações de poder".

Segundo, embora o nome Judite signifique "judia" e possa retratar uma coletividade, como discutido por Levine (2003) e outras/os pesquisadoras/ es, nosso ensaio visa abordar a personagem como uma única mulher sob a perspectiva de gênero. Até porque, ao trabalharmos com a questão de gênero não podemos supor "sujeitos universais", nem homem, nem mulher. ${ }^{4}$ Mesmo que a característica de novela seja inspirar através de um/a personagem, isso não caracteriza como sujeito universal. Isto é, nem todas as mulheres são "Judites", mas todas podem se inspirar nela, e a partir de sua vivência, serem sujeitas de suas próprias escolhas. Sendo assim, falar de Judite também é falar de Holofernes, de Ozias e os outros anciãos, e de Joaquim, e a relação estabelecida entre eles e ela, e subvertida.

A primeira parte da narrativa não há nenhum agenciamento feminino. Tudo acontece por mãos dos homens: Nabucodonosor, Holofernes, Joaquin, Aquior, Ozias. Somente a partir do cap. 8 Judite entra em cena, e tem sua ação na estória. Ela é apresentada, como já descrevemos, em seu papel normativo de viúva, a "bela, recatada e do lar". Se não se casasse com nenhum parente de seu marido falecido para cumprir a lei do levirato (cf. Dt 25,5-10), a viúva vestiria "a roupa de sua viuvez" (pano de saco), e, no caso de Judite, a piedade era característica importante.

Num primeiro momento, parece que não haverá nenhuma mudança nas relações de gênero. Cada um em seu local "determinado". Todavia, Judite subverte o seu papel. Torna-se sujeita da ação. Toma iniciativa, e, profeticamente adverte os anciãos. Não é um profeta do sexo masculino que se levanta para advertir, mas uma mulher. Já não exaltam sua beleza física, mas sua inteligência e bondade.

As relações começam a mudar. Os homens (anciãos) que deveriam, normativamente, tomar as providências frente ao cerco dos assírios, decidem

\footnotetext{
4 Para saber mais sobre a questão de sujeito universal veja: BUTLER, Judith P. Problemas de gênero: feminismo e subversão da identidade. Rio de Janeiro: Civilização Brasileira, 2016.
} 
não agir, e oram. Judite, que deveria, normativamente, orar (afinal ela era "mulher piedosa"), decide agir: "farei algo que será lembrado por gerações".

Apesar de observarmos rompimentos da ordem, e subversão das relações de gêneros, algumas características naturalizantes permanecem como a questão do "poder de sedução" da mulher. Diversas vezes na narrativa há a exaltação da beleza de Judite, e a mesma utiliza dela como "arma" para cumprir seus propósitos. Por que a mulher sempre tem como arma a sedução? A estória de Sansão e Dalila apresenta Dalila como uma mulher sedutora que, diferente de Judite, fora "o mal" para Sansão (Jz 14-16). Por outro lado, o relato da morte de Sísera por Jael, próximo à narrativa de Judite, não a descreve como bela e sedutora. Apenas como uma mulher que, estrategicamente acolhe Sísera para depois matá-lo (Jz 4,17-22).

Apesar das proximidades literárias entre Judite e Jael, a sedução é marca da ação da protagonista da novela. Diferente de Dalila, a sedução de Judite foi benéfica, foi instrumento da ação salvífica de Deus. Neste caso, a sedução é bem vista ao grupo judeu que escreveu a novela de Judite. Teria sido, então, a sedução uma estratégia de inteligência? Muito provável que, como já mencionamos, tenha sido estratégia redacional para enquadrar a sedução da mulher judia - esta só pode seduzir se for para fazer a vontade divina.

Apesar disso, Judite sabe muito bem como estabelecer as relações de poder com Holofernes. Ele com seu poder militar e sua importância como general; ela com sua astúcia, beleza e sedução. A partir de então a narrativa vai desenvolvendo essa relação até culminar no estabelecimento do poder de Judite, ao matar o general. A viúva piedosa passa a mulher ativa sexualmente (em todas as descrições, Judite está vestida para seduzir os homens), mas sem perder a sua viuvez. A mulher, que, em suas relações de gênero deveria continuar em casa, fora cumprir o papel de um soldado, ao degolar o general.

Todavia, a mulher subversiva precisa ser domesticada. De acordo com Levine (2003, p. 291), a conversão de Aquior, a presença da cabeça de Holofernes em Betúlia, e as histórias contadas sobre a viúva piedosa substituem a Judite, heroína destemia, fazendo com que se mantenha na espera pública, mas sem causar ameaça ao status quo.

\section{Considerações finais}

Por fim, considerar a novela judaica Judite sob a perspectiva de gênero leva-nos a refletir e problematizar as relações estabelecidas e subvertidas em nossa sociedade, principalmente aquelas em que há um agenciamento dos sujeitos. Ou seja, tanto homem quanto mulher se tornem agentes de suas histórias sem se "enquadrarem" em comportamentos estabelecidos. 
Por exemplo, recentemente o CNPQ publicou uma estatística do número de mestrandos e doutorandos levando em consideração faixa etária e gênero. Em relação ao gênero, em 1972, a maioria dos acadêmicos formados eram homens (cerca de 80\%), já em 2017, as mulheres mestras e doutoras eram mais que $50 \%$ dos pós-graduados. Contudo, ainda há áreas que a predominância masculina é expressiva, como a área de Teologia (80\%) são homens. ${ }^{5}$ Certamente há muitos fatores para serem considerados nesta porcentagem da área de Teologia, mas é um indício de que a desigualdade nas relações de gênero se faz presente, e indica a dificuldade que se tem, ainda em 2019, em subvertê-las.

Ademais, o desfecho da novela nos é um alerta para que a história de mulheres não sejam "domesticadas". Que nossas "Judites" não sejam substituídas pelas "viúvas piedosas", mas que sejam senhoras de suas histórias, e assim, agenciem a sua vida.

\section{Referências bibliográficas}

BÍBLIA DE JERUSALÉM. 6. reimpressão. São Paulo: Paulus, 2002.

D’AMICO, Jose Luis. Uma mujer, um pueblo y la libertad. Buenos Aires: San Pablo, 1993.

GALAZZI, Sandro; RIZZANTE, Ana Maria. Judite: a mão da mulher na história do povo. São Leopoldo; Petrópolis: Sinodal; Vozes, 2001.

LEVINE, Amy-Jill. Sacrifício e salvação: alteridade e domesticação no livro de Judite. In: BRENNER, Athalya. Ester, Judite e Susana a partir de uma leitura de gênero. São Paulo: Paulinas, 2003, p. 275-294.

MARQUES, Maria Antônia. Beleza, sedução e morte: uma leitura exegética de Judite 16,1-12.

Tese. (Tese em Ciências da Religião). Faculdade de Filosofia e Ciências da Religião, Universidade Metodista de São Paulo, São Bernardo do Campo, 2008.

SCOTT, Joan Wallach. Gênero: uma categoria útil de análise histórica. Educação e Realidade, Porto Alegre, vol. 16, n. 2, p. 5-22, 1990.

VÍLCHEZ LÍNDEZ, José. Tobias e Judite. São Paulo: Paulinas, 2006.

WHITE, Sidnie Ann. In the steps of Jael and Deborah: Judith as heroine. In: VANDERKAM, James C. No one spoke Ill of her: essays on Judith. Atlanta: Scholars Press, 1992. WILLS, Lawrence M. Ancient Jewish novels: an anthology. Oxford: Oxford University Press, 2002.

Submetido em: 26-3-2019

Aceito em: 11-6-2019

\footnotetext{
5 Confira a estatística detalha: https://www.nexojornal.com.br/grafico/2018/05/23/Qual-o- $\mathrm{g} \% \mathrm{C} 3 \%$ AAnero-e-a-idade-de-mestres-e-doutores-no-Brasil?utm_source $=$ socialbttns $\% 3$ Futm source $\% 3$ Dsocialbttns\&utm_medium $=$ Social\&utm_campaign=socialbttns
} 